\title{
Analisis Eksistensi dan Ketunggalan Solusi Model Epidemi SEIR
}

\section{Analysis of Existence dan Uniqueness Solution for SEIR Epidemic Model}

\author{
Roni Tri Putra \\ Jurusan Teknik Sipil, Politeknik Negeri Padang \\ Telp. 0751-72590 Fax. 0751-72576 Email : putra_tryronny@yahoo.co.id
}

\begin{abstract}
In this paper, it will be studied existence and uniqueness solution of equilibrium points for a SEIR model with infectious force in latent, infected and immune period. From the model it will be found investigated the existence and uniqueness solution of points its equilibrium. Existence solution of points equilibrium proved by show its differential equations system of equilibrium continue, and uniqueness solution of points equilibrium proved by show its differential equation system of equilibrium differentiable continue.
\end{abstract}

Keywords: existence solution, uniqueness solution, equilibrium points, continue, differentiable continue

\section{PENDAHULUAN}

Perkembangan ilmu pengetahuan di bidang matematika turut memberikan peranan penting dalam menggambarkan fenomena penyebaran penyakit. Peranan tersebut dituangkan dalam bentuk model matematika yang dapat dianalisis sifatsifatnya.

Penerapan model matematika dan teknik matematika untuk mendalami masalah biosciences dipelajari dalam mathematical biosciences. Salah satu cabang mathematical biosciences adalah mathematical epidemiology, yang mempelajari tentang penyebaran dan pengendalian penyakit. Mempelajari model epidemi yang didalamnya termasuk penyakit penyebab kematian pada suatu populasi total yang berubah merupakan hal penting dalam mathematical epidemiology.

Banyak model-model matematika yang telah dikembangkan, bertujuan untuk mempelajari penularan penyakit, untuk mengevaluasi penyebaran dari epidemi, dan untuk dapat mencegah adanya penyakit atau meminimalisir penyebaran dari suatu penyakit. Dalam kurun waktu yang panjang, memahami perilaku penyakit akan membantu untuk mengetahui apakah epidemi akan menghilang atau tetap berada dalam suatu populasi.
Epidemi merupakan suatu keadaan dimana berjangkitnya suatu penyakit menular dalam populasi pada suatu tempat yang melebihi perkiraan kejadian normal dalam periode yang singkat. Bila penyakit tersebut selalu terdapat dalam suatu tempat begitupun dengan faktor penyebabnya maka dikatakan Endemic, kemudian bila penyakit tersebut mempunyai ruang lingkup penyebaran yang sangat luas (global) maka disebut Pandemic.

Model epidemi adalah model matematika yang digunakan untuk mengetahui penyebaran penyakit menular, khususnya menyangkut terjadi atau tidaknya keadaan epidemi serta pengaruh yang ditimbulkan.

Berbagai macam penyakit epidemi seperti campak (measles), tubercoloses, malaria dan Human Immunodeficiency Virus (HIV) mempunyai periode laten. Periode laten adalah selang waktu dimana suatu individu terinfeksi sampai munculnya penyakit. Adanya periode laten ini menjadi alasan pembentukan model epidemi SEIR, yakni munculnya kelas exposed. Dalam tulisan ini hanya akan dibahas model epidemi SEIR.

Ada berbagai model matematika epidemi yang dikenal berdasarkan sifat atau ciri-ciri penyakitnya. Misalkan $S, E, I$ 
dan $R$ berturut - turut menunjukkan Susceptible (kelas populasi yang rentan), Exposed (kelas populasi yang laten), Infectious (kelas populasi yang terinfeksi) dan Recovered (kelas populasi yang sembuh).

Dengan berbagai asumsi, dikenal berbagai model epidemi, diantaranya SIR, SIRS, SEIR, SEIRS dan SEIS. Dalam model SIR, individu yang sembuh mempunyai kekebalan sehingga tidak lagi menjadi rentan, sedangkan untuk model SIRS individu yang sudah sembuh tidak memiliki kekebalan terhadap penyakit tersebut sehingga dapat menjadi rentan lagi. Dalam model SEIR, SEIRS dan SEIS individu yang rentan melalui masa laten setelah terinfeksi sebelum menjadi terjangkit.

Selanjutnya akan diberikan beberapa pengertian tentang fungsi diferensiabel kontinu, sistem persamaan diferensial serta kestabilan titik ekuilibrium sistem persamaan diferensial.

\section{Definisi 1.}

Diberikan fungsi $f: R^{n} \rightarrow R^{n}$, dengan $f=\left(f_{1}, f_{2}, \ldots, f_{n}\right)^{T} \in R^{n}$.

Fungsi

$f$ dikatakan diferensiabel di $x_{0} \in R^{n}$ jika terdapat transformasi linear $D f\left(x_{0}\right) \in L\left(R^{n}\right)$ dengan $L\left(R^{n}\right)$ menyatakan himpunan semua operator linear pada $R^{n}$ sehingga

$$
\lim _{h \rightarrow 0} \frac{\left\|f\left(x_{0}+h\right)-f\left(x_{0}\right)-D f\left(x_{0}\right) h\right\|}{\|h\|}=0 .
$$

$D f\left(x_{0}\right)$ disebut turunan $f$ di $x_{0}$ dan $h \in R^{n}$.

Definisi berikut memberikan penjelasan fungsi yang diferensiabel kontinu pada suatu domain.

Definisi 2.

Diberikan $f: E \subseteq \mathbb{R}^{n} \rightarrow \mathbb{R}^{n}$, $E$ himpunan terbuka. Fungsi $f$ dikatakan diferensiabel kontinu di $x_{0} \in E$ jika $f$ diferensiabel di $x_{0}$ dan $\frac{\partial f}{\partial x_{j}}, j=1,2, \ldots, n$ kontinu di $x_{0}$.
Selanjutnya $f$ dikatakan diferensiabel kontinu pada $E$, ditulis $f \in C^{\prime}\left(E, \mathbb{R}^{n}\right)$, jika $f$ diferensiabel kontinu di setiap $x \in E$.

Berikut diberikan definisi yang menunjukkan eksistensi dan ketunggalan solusi sistem persamaan diferensial.

\section{Definisi 3.}

Diberikan $E \subset R^{n}$, dengan E himpunan terbuka dan $f_{i} \in C^{\prime}(E), \quad i=1,2, \ldots, n$. Vektor $x(t)$ disebut solusi Sistem persamaan diferensial pada interval I jika $x(t)$ diferensiabel pada I dan $\dot{x}=f(x(t))$ untuk setiap $t \in I, x(t) \in E$.

Berikut didefinisikan titik ekuilibrium dan kestabilan titik ekuilibrium dari suatu sistem persamaan diferensial.

\section{Definisi 4.}

Titik $\bar{x} \in \mathbb{R}^{n}$ disebut titik ekuilibrium Sistem persamaan diferensial jika $f(\bar{x})=0$.

\section{Definisi 5.}

Titik ekuilibrium $\quad \bar{x} \in \mathbb{R}^{n} \quad$ Sistem persamaan diferensial dikatakan

a. Stabil jika untuk setiap $\varepsilon>0$ terdapat $\delta>0$ sedemikian sehingga untuk setiap solusi $x(t)$ Sistem persamaan diferensial yang memenuhi

$\left\|x\left(t_{0}\right)-\bar{x}\right\|<\delta \quad$ berakibat $\|x(t)-\bar{x}\|<\varepsilon$ untuk setiap $t \geq t_{0}$.

b. Stabil asimtotik lokal jika titik ekuilibrium $\bar{x} \in \mathbb{R}^{n} \quad$ stabil dan terdapat bilangan $\delta_{0}>0$ sedemikian sehingga untuk setiap solusi $x(t)$ yang memenuhi $\left\|x\left(t_{0}\right)-\bar{x}\right\|<\delta_{0} \quad$ berakibat $\lim _{t \rightarrow \infty} x(t)=\bar{x}$.

c. Tidak stabil jika titik ekuilibrium $\bar{x} \in \mathbb{R}^{n}$ tidak memenuhi (a).

Dari berbagai literatur belum banyak yang mengkaji model matematika epidemi SEIR secara sistematis. Sejalan dengan 
masalah yang akan dibahas, penelitian ini mempunyai tujuan sebagai berikut :

1. Membentuk model matematika epidemi SEIR pada populasi manusia

2. Menentukan titik - titik ekuilibrium model epidemi SEIR tersebut

3. Menyelidiki eksistensi dan ketunggalan solusi titik ekuilibrium model epidemi SEIR.

Hasil penelitian ini diharapkan dapat :

1. Secara umum diharapkan dapat memberikan manfaat dan sumbangan terhadap ilmu pengetahuan, serta untuk menambah wawasan khususnya dalam bidang matematika terapan.

2. Secara khusus diharapkan dapat memberikan gambaran tentang eksistensi dan ketunggalan solusi titik ekuilibrium model epidemi SEIR dengan kemampuan infeksi pada kelas laten, infeksi dan sembuh.

\section{METODOLOGI}

Metode penelitian dalam tulisan ini adalah dengan cara studi literatur serta bahan pustaka sebagai referensi untuk mempelajari model epidemi SEIR. Langkah pertama adalah dengan menentukan asumsiasumsi yang berkaitan dengan model epidemi SEIR sesuai dengan karakteristik penyakit yang dimodelkan, kemudian akan dibuat model matematika epidemi SEIR dalam bentuk sistem persamaan diferensial.

Selanjutnya, menentukan titik-titik ekuilibrium model epidemi SEIR tersebut dengan menggunakan definisi titik ekuilibrium suatu sistem persamaan diferensial. Setelah menentukan titik - titik ekuilibrium model tersebut, langkah selanjutnya menyelidiki eksistensi dan ketunggalan solusi dari titik ekuilibrium model epidemi SEIR tersebut.

Eksistensi solusi dari titik ekuilibrium model epidemi SEIR dibuktikan dengan menunjukkan bahwa sistem persamaan diferensial dari titik ekuilibrium model epidemi SEIR tersebut kontinu, sedangan ketunggalan solusi dari titik ekuilibrium model epidemi SEIR dibuktikan dengan menunjukkan bahwa sistem persamaan diferensial dari titik ekuilibrium model epidemi SEIR tersebut diferensiabel kontinu.

\section{HASIL DAN PEMBAHASAN}

Model matematika digunakan dalam banyak disiplin ilmu dan bidang studi yang berbeda. Kita dapat mencari aplikasi model matematika di bidang-bidang seperti fisika, ilmu sosial dan politik, ekonomi, bisnis dan keuangan, problem-problem jaringan komputer, serta ilmu biologi dan kedokteran. Diantara aplikasi model matematika pada bidang ilmu biologi dan kedokteran adalah model matematika yang berkaitan dengan penyakit menular. Pemodelan penyakit menular mendapat perhatian besar dalam studi epidemiologi. Tujuan utama dari pemodelan adalah menjawab peran infeksi penyakit dalam mengatur populasi alami, yaitu mengurangi fluktuasi alami populasi yang terinfeksi.

Model epidemi SEIR diterapkan pada penyakit yang memiliki masa inkubasi (masa laten) cukup lama. Pada umumnya selama masa laten tersebut individu tidak bisa menularkan penyakit, tetapi pada beberapa penyakit seperti malaria, individu yang berada dalam masa laten, infeksi dan sembuh mempunyai kemungkinan untuk menularkan penyakit. Pada model epidemi SEIR populasi dibagi menjadi 4 kelas (subpopulasi) yaitu

a. Kelas $S$ (Susceptible) menyatakan kelas individu yang rentan

b. Kelas $E$ (Exposed) menyatakan kelas individu yang telah terinfeksi tapi belum sakit (laten)

c. Kelas $I$ (Infectious) menyatakan kelas individu yang sudah terjangkit penyakit

d. Kelas $R$ (Recovered) menyatakan kelas individu yang telah sembuh dari penyakit. 
Pada pemodelan yang akan dibentuk, digunakan asumsi - asumsi sebagai berikut

a. Populasi terbuka

b. Individu yang berada dalam kelas laten, infeksi dan sembuh mempunyai kemungkinan untuk menularkan penyakit

c. Penyakit menyebabkan kematian (fatal)

d. Masa inkubasi cukup lama.

Definisi dari parameter - parameter yang digunakan pada model adalah $A$ menyatakan konstanta rekruitmen dari $S$ $\beta_{10}$ menyatakan laju dari kontak efektif pada periode laten

$\beta_{20}$ menyatakan laju dari kontak efektif pada periode infeksi

$\beta_{30}$ menyatakan laju dari kontak efektif pada periode sembuh

$\mu$ menyatakan laju kematian alami

$\alpha_{10}$ menyatakan laju kematian karena penyakit pada kelas $E$

$\alpha_{20}$ menyatakan laju kematian karena penyakit pada kelas $I$

$\gamma_{0}$ menyatakan laju dari kelas $E$ ke kelas $I$ $k_{0}$ menyatakan laju kesembuhan.

Formulasi modelnya adalah :

$\frac{d S}{d t}=A-\beta_{10} S E-\beta_{20} S I-\beta_{30} S R-\mu S$

(1)

$$
\begin{aligned}
& \frac{d E}{d t}=\beta_{10} S E+\beta_{20} S I+\beta_{30} S R-\gamma_{0} E- \\
& \left(\mu+\alpha_{10}\right) E
\end{aligned}
$$

$\frac{d I}{d t}=\gamma_{0} E-k_{0} I-\left(\mu+\alpha_{20}\right) I$

$$
\frac{d R}{d t}=k_{0} I-\mu R
$$

Diberikan $N(t)$ menyatakan ukuran populasi pada saat $t$, maka

$$
N(t)=S(t)+E(t)+I(t)+R(t) .
$$

Untuk menyederhanakan Sistem (1) s.d (4) dimisalkan $\mu d t=d \tau$ atau $\tau=\mu t$, maka Sistem (1) s.d (4) menjadi :

$\frac{d S}{d \tau}=\frac{A}{\mu}-\beta_{1} S E-\beta_{2} S I-\beta_{3} S R-S$

$\frac{d E}{d \tau}=\beta_{1} S E+\beta_{2} S I+\beta_{3} S R-(1+\gamma+$

$\left.\alpha_{1}\right) E$

$\frac{d I}{d \tau}=\gamma E-\left(1+k+\alpha_{2}\right) I$

$\frac{d R}{d \tau}=k I-R_{y}$

dengan

$\beta_{1}=\frac{\beta_{10}}{\mu}, \beta_{2}=\frac{\beta_{20}}{\mu}, \beta_{3}=\frac{\beta_{30}}{\mu}, \gamma=\frac{\gamma_{0}}{\mu}, \alpha_{1}=$ $\frac{\alpha_{10}}{\mu}, \alpha_{2}=\frac{\alpha_{20}}{\mu}, k=\frac{k_{0}}{\mu}$.

Jika $S=N-E-I-R$ disubstitusikan ke dalam Sistem (5) sampai dengan (8) diperoleh

$\frac{d E}{d \tau}=\left(\beta_{1} E+\beta_{2} I+\beta_{3} R\right)(N-E-I-R)-$ $\delta E$

$\frac{d I}{d \tau}=\gamma E-\omega I$

$\frac{d R}{d \tau}=k I-R$

$\frac{d N}{d \tau}=\frac{A}{\mu}-N-\alpha_{1} E-\alpha_{2} I_{s}$

dengan $\delta=1+\gamma+\alpha_{1}$

$\omega=1+k+\alpha_{2}$.

\section{Titik Ekuilibrium}

Titik ekuilibrium Sistem (5) sampai dengan (8) diperoleh dengan menjadikan ruas kanan masing - masing persamaan sama dengan nol, dan diperoleh :

$$
S=\frac{A\left(\alpha_{1} \omega+\alpha_{2} \gamma\right)}{\left(\beta_{1} \omega+\beta_{2} \gamma+\beta_{\mathrm{g}} k \gamma\right)(A-\mu N)+\mu\left(\alpha_{1} \omega+\alpha_{2} \gamma\right)}
$$

$E=\frac{\omega[A-\mu N]}{\mu\left(\omega \alpha_{1}+\gamma \alpha_{2}\right)}$ 
$I=\frac{\gamma[A-\mu N]}{\mu\left(\alpha_{1} \omega+\alpha_{2} \gamma\right)}$

$R=\frac{k \gamma[A-\mu N]}{\mu\left(\alpha_{1} \omega+\alpha_{2} \gamma\right)}$

Selanjutnya akan diberikan beberapa teorema tentang fungsi diferensiabel kontinu, sistem persamaan diferensial serta kestabilan titik ekuilibrium sistem persamaan diferensial. Jika suatu fungsi diketahui diferensiabel maka turunan parsialnya selalu ada. Berikut secara formal diberikan teoremanya.

\section{Teorema 1.}

Diberikan $f_{i}: E \subset R^{n} \rightarrow R, \quad i=1,2, \ldots, n$, dan $f: E \subset R^{n} \rightarrow R^{n}, \quad$ dengan $f=\left(f_{1}, f_{2}, \ldots, f_{n}\right)^{T} \in E$ dan $E$ himpunan terbuka. Jika fungsi $f$ diferensiabel di $x_{0} \in E$, maka $\frac{\partial f_{i}}{\partial x_{j}}, i, j=1,2, \ldots, n$ ada di $x_{0}$ dan untuk setiap $x_{0} \in E$ berakibat $D f\left(x_{0}\right) x=\sum_{j=1}^{n} \frac{\partial f\left(x_{0}\right)}{\partial x_{j}} x_{j}$, dengan

$$
\frac{\partial f}{\partial x_{j}}=\left[\frac{\partial f_{1}}{\partial x_{j}}, \frac{\partial f_{2}}{\partial x_{j}}, \ldots, \frac{\partial f_{n}}{\partial x_{j}}\right]^{T} \text {. }
$$

Syarat perlu dan cukup supaya suatu fungsi diferensiabel kontinu diberikan oleh teorema berikut.

\section{Teorema 2.}

Diberikan $f: E \subseteq \mathbb{R}^{n} \rightarrow \mathbb{R}^{n}$, E himpunan terbuka. Fungsi $f$ dikatakan diferensiabel kontinu pada E jika dan hanya jika $\frac{\partial f}{\partial x_{j}}$, $j=1,2, \ldots, n$ ada dan kontinu pada $E$.

\section{Sistem Persamaan Diferensial}

Diberikan sistem persamaan diferensial $\dot{x}_{1}=f_{1}\left(x_{1}, x_{2}, \ldots, x_{n}\right)$

$$
\dot{x}_{2}=f_{2}\left(x_{1}, x_{2}, \ldots, x_{n}\right)
$$

$$
\vdots
$$$$
\dot{x}_{n}=f_{n}\left(x_{1}, x_{2}, \ldots, x_{n}\right) \text {, }
$$

dengan $f_{i}: E \subset R^{n} \rightarrow R, i=1,2, \ldots, n$, dan $\left(x_{1}, x_{2}, \ldots, x_{n}\right) \in E \subset R^{n}$.

Kemudian diberikan kondisi awal Sistem (17) yaitu $x_{i}\left(t_{0}\right)=x_{i 0}, i=1,2, \ldots, n$. Sistem (1) dapat ditulis sebagai

$\dot{x}=f(x)$

dengan $x=\left(x_{1}, x_{2}, \ldots, x_{n}\right) \in E \subset R^{n}$, $f=\left(f_{1}, f_{2}, \ldots, f_{n}\right)^{T} \in R^{n}$ dan kondisi awal $x\left(t_{0}\right)=x_{0}=\left(x_{10}, x_{20}, \ldots, x_{n 0}\right) \in E$.

Selanjutnya, notasi $\quad x(t)=x\left(x_{0}, t\right)$ merupakan solusi Sistem (18) yang dimulai dari $x_{0}$.

Berikut diberikan teorema yang menunjukkan eksistensi dan ketunggalan solusi Sistem (18).

\section{Teorema 3.}

Jika $\quad E \subset \mathbb{R}^{n}{ }^{n}, E \quad$ terbuka, $f_{i} \in C^{\prime}(E, \mathbb{R}), i=1,2, \ldots, n \quad$ dan $\quad x_{0} \in E$ maka terdapat $a>0$ sehingga masalah nilai awal $\dot{x}=f(x)$ dengan $x(0)=x_{0}$ mempunyai penyelesaian tunggal $x(t)$ pada interval $[-a, a]$.

\section{Kestabilan Titik Ekuilibrium Sistem Persamaan Diferensial}

Berikut ini diberikan sistem persamaan diferensial linear

$$
\begin{gathered}
\dot{x}_{1}=a_{11} x_{1}+a_{12} x_{2}+\ldots+a_{1 n} x_{n} \\
\dot{x}_{2}=a_{21} x_{1}+a_{22} x_{2}+\ldots+a_{2 n} x_{n} \\
\vdots \\
\dot{x}_{n}=a_{n 1} x_{1}+a_{n 2} x_{2}+\ldots+a_{n n} x_{n}
\end{gathered}
$$

dengan $\left(x_{1}, x_{2}, \ldots, x_{n}\right) \in E \subset R^{n} . \quad$ Sistem (19) dapat ditulis dalam bentuk

$$
\dot{x}=A x
$$

dengan $x \in E$ dan $A$ matriks ukuran $n \times n$. Selanjutnya, diberikan sistem

$\dot{x}=f(x)$

dengan $x \in E \subset R^{n}$ dan $f: E \subset R^{n} \rightarrow R^{n}$ fungsi kontinu pada $E$. Sistem (20) disebut sistem nonlinear, jika sistem tersebut tidak dapat dinyatakan dalam bentuk Sistem (19). 


\section{Eksistensi dan Ketunggalan Solusi}

Sistem (5) s.d (8) dapat ditulis dengan

$\frac{d S}{d \tau}=g_{1}(S, E, I, R)=\frac{A}{\mu}-\beta_{1} S E-\beta_{2} S I-$

$\beta_{3} S R-S$

$\frac{d E}{d \tau}=g_{2}(S, E, I, R)=\beta_{1} S E+\beta_{2} S I+$

$\beta_{3} S R-\left(1+\gamma+\alpha_{1}\right) E$

$\frac{d I}{d \tau}=g_{3}(S, E, I, R)=\gamma E-\left(1+k+\alpha_{2}\right) I$

$\frac{d R}{d \tau}=g_{4}(S, E, I, R)=k I-R$.

Teorema 4. Sistem (21) sampai dengan (24) mempunyai solusi yang tunggal.

\section{Bukti}

(i). Akan dibuktikan fungsi - fungsi diatas adalah fungsi - fungsi yang kontinu pada $\mathbb{R}^{4}$.

(a).

Fungsi

$g_{1}(S, E, I, R)=\frac{A}{\mu}-\beta_{1} S E-\beta_{2} S I-\beta_{3} S R-$

$S$

kontinu pada $\mathbb{R}^{4}$.

Misalkan

$g_{1}(S, E, I, R)=h_{1}(S, E, I, R)+$

$h_{2}(S, E, I, R)+h_{3}(S, E, I, R)+$

$h_{4}(S, E, I, R)+h_{5}(S, E, I, R)$

, dengan

$h_{1}(S, E, I, R)=\frac{A}{\mu}$,

$h_{2}(S, E, I, R)=-\beta_{1} S E$,

$h_{3}(S, E, I, R)=-\beta_{2} S I$,

$h_{4}(S, E, I, R)=-\beta_{3} S R$ dan

$h_{5}(S, E, I, R)=-S$.

( a.1)Fungsi $h_{1}(S, E, I, R)=\frac{A}{\mu}$ adalah fungsi

konstan, maka fungsi tersebut kontinu pada $\mathbb{R}^{4}$.

(a.2) Diperhatikan fungsi

$$
h_{2}(S, E, I, R)=-\beta_{1} S E
$$

Diambil sebarang $(\bar{S}, \bar{E}, \bar{I}, \bar{R}) \in \mathbb{R}^{4}$.

Diberikan bilangan $\varepsilon>0$ sebarang. Akan dibuktikan terdapat $\delta>0$ sehingga untuk setiap $(S, E, I, R) \in \mathbb{R}^{4}$ dengan

$\|(S, E, I, R)-(\bar{S}, \bar{E}, \bar{I}, \bar{R})\|<\delta_{y}$ berlaku

$$
\left\|h_{2}(S, E, I, R)-h_{2}(\bar{S}, \bar{E}, \bar{I}, \bar{R})\right\|<\varepsilon .
$$

Untuk setiap $(S, E, I, R) \in \mathbb{R}^{4}$, jika $\|(S, E, I, R)-(\bar{S}, \bar{E}, \bar{I}, \bar{R})\| \leq 1$ diperoleh $|S|-|\bar{S}| \leq|S-\bar{S}| \leq \|(S, E, I, R)-$ $(\bar{S}, \bar{E}, \bar{I}, \bar{R}) \| \leq 1$

Sehingga

$$
|S| \leq 1+|\bar{S}| .
$$

Akibatnya diperoleh

$$
\begin{gathered}
\left\|h_{2}(S, E, I, R)-h_{2}(\bar{S}, \bar{E}, \bar{I}, \bar{R})\right\|=\left\|-\beta_{1} S E-\left(-\beta_{1} \bar{S} \bar{E}\right)\right\| \\
=\left\|-\beta_{1}(S E-\bar{S} \bar{E})\right\| \\
=\left\|-\beta_{1}\right\|\|(S E-\bar{S} \bar{E})\| \\
=\beta_{1}\|S E-\bar{S} \bar{E}\| \\
=\beta_{1}\|S E-S \bar{E}+S \bar{E}-\bar{S} \bar{E}\| \\
=\beta_{1}\|S(E-\bar{E})+\bar{E}(S-S)\| \\
\leq \beta_{1}[|S|\|E-\bar{E}\|+|\bar{E}|\|S-\bar{S}\|] \\
\leq \beta_{1}[|S|+|\bar{E}|]\|(S-\bar{S})+(E-\bar{E})\| \\
\leq \beta_{1}[|S|+|\bar{E}|]\|(S, E)-(\bar{S}, \bar{E})\| \\
\leq \beta_{1}[|\bar{S}|+|\bar{E}|+1]\|(S, E)-(\bar{S}, \bar{E})\|
\end{gathered}
$$

Pilih $\delta=\min \left\{1, \frac{s}{\beta_{1}[|S|+|\bar{E}|+1]}\right\}, \quad$ dengan demikian dari Persamaan (26) diperoleh $\left\|h_{2}(S, E, I, R)-h_{2}(\bar{S}, \bar{E}, \bar{I}, \bar{R})\right\|$ $\leq \beta_{1}[|S|+|\bar{E}|+1]\|(S, E)-(\bar{S}, \bar{E})\|<\varepsilon$. Jadi Fungsi (25) kontinu pada $\mathbb{R}^{4}$.

(a.3) Fungsi $h_{3}(S, E, I, R)=-\beta_{2} S I$ kontinu, analog dengan (i) bagian (a.2).

(a.4) Fungsi $\quad h_{4}(S, E, I, R)=-\beta_{3} S R$ kontinu, analog dengan (i) bagian (a.2) . (a.5) Diperhatikan fungsi linear $h_{5}(S, E, I, R)=-S$

Diambil sebarang $(\bar{S}, \bar{E}, \bar{I}, \bar{R}) \in \mathbb{R}^{4}$.

Diberikan bilangan $\varepsilon>0$ sebarang. Dipilih $\delta=\varepsilon$, sehingga untuk setiap $(S, E, I, R) \in \mathbb{R}^{4}$ dengan $\|(S, E, I, R)-(\bar{S}, \bar{E}, \bar{I}, \bar{R})\|<\delta$, berlaku

$$
\begin{aligned}
& \left\|h_{5}(S, E, I, R)-h_{5}(\bar{S}, \bar{E}, \bar{I}, \bar{R})\right\|= \\
& |-S-(-\bar{S})| \\
& \quad=|-1||S-\bar{S}| \\
& \quad=|S-\bar{S}|
\end{aligned}
$$




$$
\begin{aligned}
& \leq\|(S, E, I, R)-(\bar{S}, \bar{E}, \bar{I}, \bar{R})\| \\
& <\delta=\varepsilon .
\end{aligned}
$$

Jadi Fungsi (27) kontinu pada $\mathbb{R}^{4}$. Karena fungsi-fungsi $h_{1}, h_{2}, h_{3}, h_{4}, h_{5}$ kontinu pada $\mathbb{R}^{4}$, maka $g_{1}$ kontinu pada $\mathbb{R}^{4}$.

Bukti untuk fungsi - fungsi $g_{2}, g_{3}, g_{4}$ analog dengan (i) bagian (a).

Jadi terbukti bahwa fungsi - fungsi pada Sistem (21) s.d (24) kontinu pada $\mathbb{R}^{4}$.

(ii). Akan dibuktikan bahwa Sistem (21) s.d (24) merupakan fungsi diferensiabel kontinu pada $\mathbb{R}^{4}$.

(a). Turunan parsial fungsi $g_{1}$ terhadap $S, E, I, R$ adalah

$$
\begin{aligned}
& \frac{\partial g_{1}(x)}{\partial S}=-\beta_{1} E-\beta_{2} I-\beta_{3} R-1 \\
& \frac{\partial g_{1}(x)}{\partial E}=-\beta_{1} S \\
& \frac{\partial g_{1}(x)}{\partial I}=-\beta_{2} S \\
& \frac{\partial g_{1}(x)}{\partial R}=-\beta_{3} S .
\end{aligned}
$$

Turunan parsial terhadap $S, E, I, R$ merupakan fungsi linear sehingga merupakan fungsi kontinu, bukti analog dengan (i) bagian (a.2). Karena semua turunan parsialnya ada dan kontinu pada $\mathbb{R}^{4}$ maka dapat disimpulkan fungsi $g_{1}$ diferensiabel kontinu pada $\mathbb{R}^{4}$.

(b). Fungsi - fungsi $g_{2}, g_{3}, g_{4}$ merupakan fungsi diferensiabel kontinu, bukti analog dengan (ii) bagian a.

Berdasarkan pembuktian (i) dan (ii) maka fungsi - fungsi pada Sistem (21) s.d (24) kontinu dan diferensiabel kontinu pada $\mathbb{R}^{4}$.

\section{SIMPULAN}

Adapun kesimpulan dari penelitian ini adalah

1.Model epidemi SEIR merupakan model penyebaran penyakit yang terjadi pada kelompok-kelompok individu yang berbeda, yaitu kelas susceptible (kelas individu yang rentan penyakit), kelas exposed (kelas individu yang telah terinfeksi namun belum sakit atau masa laten), kelas infected (kelas individu yang telah terjangkit penyakit) dan kelas recovered (kelas individu yang telah sembuh).

2. Model matematika epidemi SEIR dengan adanya kemampuan infeksi pada periode laten, infeksi dan sembuh adalah :

$$
\begin{aligned}
& \frac{d S}{d t}=A-\beta_{10} S E-\beta_{20} S I-\beta_{30} S R-\mu S \\
& \frac{d E}{d t}=\beta_{10} S E+\beta_{20} S I+\beta_{30} S R-\gamma_{0} E- \\
& \left(\mu+\alpha_{10}\right) E
\end{aligned}
$$

$$
\begin{aligned}
& \frac{d I}{d t}=\gamma_{0} E-k_{0} I-\left(\mu+\alpha_{20}\right) I \\
& \frac{d R}{d t}=k_{0} I-\mu R .
\end{aligned}
$$

3.Eksistensi solusi dari titik ekuilibrium model epidemi SEIR dibuktikan dengan menunjukkan sistem persamaan diferensial dari titik ekuilibrium model epidemi SEIR tersebut kontinu, dan untuk membuktikan bahwa solusi dari titik ekuilibrium model epidemi SEIR tunggal adalah dengan menunjukkan bahwa sistem persamaan diferensial dari titik ekuilibrium model epidemi SEIR tersebut diferensial kontinu.

\section{SARAN}

Karena berbagai keterbatasan, penulis menyadari penelitian dan tulisan ini masih banyak kekurangannya. Banyak hal yang belum tercakup dalam penelitan ini. Perlu dikaji lebih lanjut generalisasi untuk kestabilan model epidemi lainnya dan simulasi numeriknya.

\section{DAFTAR PUSTAKA}

Anton H, dan Rorres,C.,2004. Aljabar Linear Elementer Versi Aplikasi, Edisi Kedelapan, alih bahasa oleh Indriasari,R dan Harmaen,I., Erlangga, Jakarta.

Arrowsmith, D.R. dan Place, C.M., 1992, Dynamical System Differential Equation, Maps and Chaotic Behaviour, Chapman \& Hall Mathematic, London.

Bazaraa, M.S., Sheraly, H.D, and Shetty, C.M., Nonlinear Programming Theory and Algorithms, John Wiley \& Sons, Inc, New York, 1993. 
Becerra, M.V., 2008. La Salle's Invariant Set Theory, http://www.personal.rdg.ac.uk/ shs99v $\mathrm{mb} /$ notes/anc/lecture3.pdf

Boyd, Stephen, 2008, Basic Lyapunov Theory, Stanford University, http://www.stanford.edu/class/ee363/lya p.pdf

Capazzo, V., Mathematical Structures of Epidemic Systems, Springer-Verlag, Heidelberg, 2008.

Chong, K.P and Stainslow, H.Z., An Introduction to Optimization, John Wiley \& Sons, University of New Hampshire, 1984.

Gantmacher, F.R., 1959, The Theory of Matrices, Chelsea Publishing Company, New York.

Hanh, Wolfgang, 1967, Stability of Motion, Springer - Verlag, New York.

Hirsch, M.W., dan Smith, Monotone Dynamical Systems, University of California, Berkeley, 2004.

Iwami. S, Takeuchi, Y., dan Liu, X., 2007. Avian - human Influenza Epidemic Model, Mathematical Biosciences 2007, hal 1-25.

Feng J., dan Hadeler,K.P., Qualitative Behaviour of Some Simple Networks, Mathematical Gen. 1996, hal 5019-5033.

Kocak, H. dan Hole, J.K., 1991, Dynamic and Bifurcation, Springer - Verlag, New York.

Leon, J.S., Aljabar Linear dan Aplikasinya, Edisi Kelima, Alih bahasa olehBondan,A. Erlangga, Jakarta, 1998.

Luenberger, G.D., 1979, Introduction to Dynamic System Theory, Models \& Aplication, John Wiley \& Sons, New York.

Olsder, G.J., 1994, Mathematical System Theory, Delftse Uitgevers Maatschappij, Netherlands.
Perko L., 1991, Differential Equations and Dynamical Systems, Springer - Verlag, New York.

Ross, S.L., Differential Equations, $3^{\text {rd }}$ edition, John Wiley \& Sons, University of New Hampshire, 1984. 